\title{
Escrever poemas: vozes em busca de um autor
}

Ana Elvira Luciano Gebara*

UNICSUL / Direito

Fundação Getúlio Vargas.

Este artigo integra o dossiê

A produção de textos na

Olimpíada de Língua

Portuguesa. Em consequência, pressupõe o conhecimento dos pressupostos teóricos e metodológicos da própria Olimpíada, tais como caracterizados na "Introdução" ao dossiê. A análise incidiu sobre 387 produções de alunos do quinto e do sexto ano do Ensino Fundamental público; e tomou como objeto de análise as marcas de autoria manifestas no processo de elaboração desses textos.

\section{RESUMO}

No ensino-aprendizagem da produção escrita, o trabalho com gêneros envolve escolhas que se refletem nos textos dos alunos. A análise da amostra dos poemas da Olimpíada possibilitou a elaboração de um quadro das escolhas de professores e de alunos ao longo do processo de elaboração dos textos poéticos, permitindo identificar o elemento central para a produção desses gêneros: as marcas de autoria. Em busca do autor que sustenta o poema - na perspectiva da concepção bakhtiniana de autoria (FARACO, 2005, p. 45) e, ainda, com base nas indicações de Fiad (2008, p. 218), podemos dizer que essas marcas estariam no "como", no "processo de transposições refratadas", "na singularidade e no estilo", e também "no viés valorativo". Assim, em cada poema da amostra buscou-se analisar os elementos que surgem, vozes que se entrelaçam e indicam a sujeição ou a solução para a voz do aluno-poeta.

\section{PALAVRAS-CHAVE}

Marcas da autoria. Gêneros Poéticos. Escrita de poema. 
Ensinar a escrever pelos gêneros é sempre uma tarefa de escolhas. Quando se trata dos gêneros poéticos, essas escolhas se intensificam, porque ensinar poema é colocar sob o foco das atividades uma gama enorme de gêneros que se caracterizam pelo uso do verso, pela circulação na esfera literária e pela autoridade do poeta, voz centralizadora do texto.

Essas escolhas, sempre anteriores ao momento da produção textual, se refletem como representações do que seriam os gêneros poéticos. Por essa razão, neste artigo, o resultado da análise da amostra de poemas inscritos na Olimpíada 2010 aponta para representações cruzadas do que seria o poema, o poeta e o escrever poema, o que possibilita uma reflexão capaz de contribuir para que se avance no ensino da escrita de poema pela ampliação dessas imagens.

Escaneadas para a análise, as 387 produções que constituíram a amostra (cerca de $10 \%$ do total de inscritos) indicavam certa dicção de cada um dos alunospoetas - elemento que será oportunamente retomado. Os poemas eram de todos os estados participantes e incluíam textos finalistas e não finalistas.

A primeira aproximação de análise foi feita com base nos critérios de avaliação oferecidos pelo material da Olimpíada: a) sonoridade; b) recursos de estilo; c) aspectos gráficos; d) singularidade (esses quatro critérios, presentes no CD sobre avaliação dos textos, têm como objetivo caracterizar o poema para a comissão avaliadora); e) tema; f) adequação ao gênero (discursiva e linguística); g) marcas de autoria; h) convenções da escrita (esses quatro últimos presentes no fascículo que orienta a produção dos poemas e a comissão avaliadora).

Os critérios apontavam para uma concepção de poesia que deveria ser percebida e, para que o processo da produção e avaliação fosse bemsucedido, adotada pelos alunos-poetas e pela comissão avaliadora. Os critérios "sonoridade"; "aspectos gráficos"; "adequação ao gênero (apenas a adequação linguística)" se referem à estrutura composicional do poema; ou seja, no texto poético, o trabalho com a linguagem (sons, figuras de linguagem, escolha lexical, arranjo sintático) e com a distribuição gráfica do texto na página (versos, estrofes ou arranjos visuais significativos) é considerado central para a identificação de que estamos diante de um poema e que, dessa forma, houve a adesão do aluno ao gênero.

Já os critérios "tema” e "convenções da escrita" são transversais, uma vez que se espera que o tratamento dado ao tema, em cada um dos gêneros, não 
se afaste daquilo que foi proposto, e que as convenções da escrita (ortografia, concordância, regência) estejam adequadas à variante e à criação lexical presente no texto. Quando se abordam os gêneros poéticos, é importante lembrar que a forma significa (COHEN, 1978) e que, na estruturação dos elementos constitutivos do poema, elabora-se o tema. A mesma afirmação poderia ser estendida, com as devidas mudanças, a qualquer gênero. Um mesmo tema é tratado de várias maneiras, não somente pela diversidade de pontos de vista, mas pela adoção de um ou outro gênero. Se pensarmos em "Poema tirado de uma notícia de jornal", ${ }^{1}$ a abordagem da morte de João Gostoso seria muito diferente nos jornais, porque o gênero notícia pressupõe outra organização temática, uma vez que tem função informativa e circula em outros suportes e esfera. A morte de João Gostoso seria ainda mais distante do poema no relatório do legista. No poema, espera-se que a subjetividade daquele que escreve aflore, marcando nos versos uma avaliação axiológica do tema que escolheu. O critério “tema”, dentro dessa questão genérica, procurava garantir que o aluno-poeta não se esquecesse de considerar como matéria poética os aspectos que julgasse pertinentes do lugar em que vive.

Quanto às convenções da escrita, esse critério traz para a produção textual a questão da revisão e da escolha consciente de variantes e recursos linguísticos. Se o aluno-poeta não respeita a concordância e isso fizer sentido no verso, pois ele representa a voz das pessoas simples de sua cidade, houve respeito às convenções da variante escolhida - ele não pode ser penalizado por isso. No entanto, se a não observação das convenções da escrita não corresponder a um recurso expressivo, o que ocorreu foi a falta de revisão do texto para ser enviado à Olimpíada. As convenções são importantes nas interações realizadas pelo texto escrito e devem ser observadas e utilizadas de forma consciente. Se, no poema, é possível escolher entre convenção ou transgressão, em outros gêneros, como o artigo de opinião, essa escolha não é dada ao escritor.

Embora todos os critérios tenham sido utilizados para a primeira recolha de dados, os critérios "singularidade", "recursos de estilo" e "marcas da autoria" foram centrais no processo de análise para avaliar a efetividade das orientações do Caderno Poetas da Escola (CENPEC, 2010) e a subsequente compreensão, pelos professores, no processo de ensino da escrita do poema,

“Poema tirado de uma notícia de jornal”, de Manuel Bandeira (do livro Libertinagem, In: BANDEIRA, M. Estrela da Vida inteira. 19. ed. Rio de Janeiro: José Olympio, 1991. p. 107), cujo verso inicial é "João gostoso era carregador e de feira livre e morava no Morro da Babilônia num barracão sem número". 
já que questões relacionadas ao gênero são geradas nesses três critérios. A "singularidade", como característica poética, é descrita como:

(...) o conjunto dos vários elementos presentes no poema que permitirá perceber a particularidade ou a singularidade do discurso poético, que o diferencia de qualquer outro uso linguístico: o discurso poético não tem qualquer objetivo prático. Não se faz poemas para informar, criticar, justificar, avisar, opinar etc. Trata-se de um jogo, de um exercício gratuito da linguagem onde o que interessa é expressar-se esteticamente. Daí a liberdade de expressão que o poema pressupõe.

Assim, os elementos sonoros, gráficos e estilísticos são usados no poema não com objetivo prático, mas para garantir que o conjunto desses elementos o torne único, singular. É exatamente isso que deve estar presente para se avaliar um poema: em que medida e de que maneira essa singularidade teria sido atingida pelo aluno.

Com essas características, a singularidade remete à concepção de poema em que o estabelecimento do referente interno de um contexto enunciativo criado a partir dos elementos constitutivos do poema define sua legitimidade. Esse critério, que exige do aluno-poeta a força de criação desse contexto enunciativo, é aliado às “marcas de autoria”.

A autoria pode ser tomada como um valor em si e estudada como tal; no trabalho com o gênero, porém, passa a ser parametrizada pelas coerções que os gêneros oferecem ao escritor. Ser autor é participar do dialogismo constitutivo da linguagem e conseguir um arranjo próprio que revele a identidade e a inserção do olhar do escritor no mundo. Como afirma Faraco, sobre a concepção bakhtiniana de autor,

O autor-criador é, assim, quem dá forma ao conteúdo: ele não apenas registra passivamente os eventos da vida (ele não é um estenógrafo desses eventos), mas, a partir de uma certa posição axiológica, recorta-os e reorganiza-os esteticamente.

$O$ ato criativo envolve, desse modo, um complexo processo de transposições refratadas da vida para a arte: primeiro, porque é um autor-criador e não o autor-

pessoa que compõe o objeto estético (há aqui, portanto, já um deslocamento refratado, à medida que o autor-criador é uma posição axiológica conforme recortada pelo autor-pessoa); e, segundo, porque a transposição de planos da vida para a arte se dá não por meio de uma isenta estenografia (o que seria impossivel, na concepção bakhtiniana), mas a partir de um certo viés valorativo (aquele consubstanciado no autor-criador). (2005, p. 39)

O poema exige discursivamente que o autor-poeta seja autor-criador, pois é a seleção, o domínio e a escolha consciente dos elementos constitutivos dos gêneros poéticos que permitirá a assunção de um "viés valorativo" e a reorganização estética dos eventos. 
As “marcas de autoria” são definidas, nos critérios de avaliação, por meio das seguintes perguntas: a) o título do poema motiva a sua leitura?; b) o poema envolve o leitor por meio de recursos e procedimentos efetivamente literários?; c) por suas escolhas e recursos, o poema pode surpreender e seduzir o leitor? Como se observa, o tratamento discursivo dado à autoria do poema, na Olimpíada, está imbricado com os critérios composicionais do gênero. Isso converge com a questão da autoria tal como Fiad apresenta em seu texto "Ensino e autoria", ao retomar as ideias de Possenti:

- a noção de autoria deve ser pensada junto às noções de singularidade e estilo;

- a autoria é detectável através de indícios e aqui deve remeter-se às considerações de Ginzburg (1986) sobre o paradigma indiciário;

- para se dizer que um texto tem autoria, não é suficiente que ele seja um texto correto gramaticalmente, nem que seja textualmente satisfatório. Isso significa que, na sua visão, as marcas de autoria são da ordem do discurso e não da gramática ou do texto;

- duas atitudes de um autor seriam “dar voz aos outros” e "manter distância” em relação ao que dizem e em relação a seus interlocutores;

- a autoria é encontrada no "como" e não no "o quê" é expresso. (FIAD, 2008, p. 218)2

Assim, a noção de que a autoria está no "como" e de que o autor tem duas atitudes, "dar voz aos outros" e "manter distância", permitiu o estabelecimento de parâmetros para a análise dos poemas da amostra. Buscou-se, então, o autor-criador como aquele que imprimiria ao seu poema o que se almejava com a sequência didática proposta no Caderno Poetas da Escola e no material de apoio. Não se tratava, portanto, de avaliar novamente os poemas, mas de verificar, por meio das marcas das escolhas efetivadas, em que medida as oficinas haviam sido efetivas e se as representações de poema tinham sido ampliadas. Iniciou-se, assim, a procura pela voz do autor.

\section{OLHAR PELA PRIMEIRA VEZ}

Antes de apresentar os resultados de análise, é importante observar que, por se tratar de um processo que não começou no contato com a amostra, mas com a discussão e com a convivência com os próprios atores (professores e equipe técnica) e autores (alunos-poetas, nesse caso) da Olimpíada, nas etapas de avaliação, precisávamos de uma postura que permitisse a leitura do poema à

O trabalho de Carlo Ginzburg citado por Raquel Fiad é Mitos, emblemas, sinais: morfologia e história. São Paulo: Companhia das Letras, 1986. 
nossa frente, e não de um texto a ser escrutinado. ${ }^{3} \mathrm{O}$ que nos auxiliou nesse processo foi o fato de os textos originais terem sido escaneados, pois isso instaurou novamente a relação poeta - leitor, dois sujeitos mediados pelo poema, em virtude da letra manuscrita que indicava uma “dicção" própria das linhas e da ocupação da página.

\section{TíTULO: CHAVES PARA A LEITURA}

Um dos elementos que se sobressaem nos poemas é o título. Os títulos podem ser chaves, como as claves o são nas partituras, e permitir que a atribuição de sentidos do tema seja feit a partir daquele “tom". Em outros casos, eles podem indicar imediatamente o tema em si ou ainda iniciar o poema fazendo parte dele, tal como os versos que o seguem. Em qualquer um desses casos, o título é parte da coerência do texto que é estabelecida, no caso do poema, por uma lógica interna, uma espécie de unidade que se estende por todos os versos.

Nos textos da amostra, os títulos se dividiam em dois grupos. 0 primeiro não trazia elaboração aparente. Era a reprodução ou uma explicitação do título dado no caderno do professor, Poetas da Escola. No primeiro caso, houve decalque de "o lugar onde vivo" sem nenhuma alteração. No segundo, explicitou-se o sujeito da oração adjetiva - "o lugar onde eu vivo", mantendo-se o restante. Em ambos os casos, o que se observa é a manutenção da orientação fornecida pelo material, sem a intervenção desse eu que supostamente deveria explicitar sua relação com o lugar, buscando a atenção do leitor por elementos que o preparassem para o envolvimento com o poema.

A conservação do tema sugere uma não personalização do lugar, uma vez que esse tipo de título poderia remeter o leitor a um lugar indefinido, uma espécie de quadro que cada "eu”, ou seja, cada leitor, poderia preencher com sua experiência. Esse tipo de estratégia, porém, indica um processo de elaboração pouco criativo e sem o comprometimento do poeta com seu tema, pois não sugere a consideração do lugar pelo eu lírico.

O segundo grupo trazia traços de autoria. Havia diversos sintagmas nominais que, retomando o referente (nome da cidade ou lugar escolhido para ser representado), já mostravam a avaliação que o enunciador nos poemas, o eu lírico, fazia do tema representado em seus versos. Tratava-se de títulos

Em diferentes ocasiões, a autora participou do processo de avaliação da Olimpíada e da elaboração de seus materiais [nota dos editores].

É importante relatar que todos os poemas da amostra (387) apresentavam a configuração de versos na página pautada. 
como os destacados a seguir: "Minha cidadezinha"; "Amizade"; "Olhos de menina" entre outros. Nesse grupo, a ancoragem temática se faz de modo a conduzir o leitor a uma imagem (Em "Olhos de menina" surge a imagem dos olhos e o leitor deve percorrer os versos para saber a quem se referem esses olhos. Menina seria a cidade ou o poeta?); a uma posição em relação ao tema ("Minha cidadezinha" - nesse caso, a forma diminutiva "cidadezinha" além de rimar com o pronome possessivo "minha" situa o lugar perto do poeta numa relação afetiva) ou a um conceito (“Amizade" - esse conceito pode ser o que constitui a cidade, ou o que o poeta vive na cidade; ou seja, uma forma de instigar o leitor a percorrer os versos). Recupera-se, nesses casos do segundo grupo, o papel fundador da nomeação - indicador do envolvimento do aluno-poeta com o tema e a própria escrita do poema.

EU VARIO, TU “VAREIAS”

Outro elemento linguístico relevante derivado da leitura da amostra foi o uso das variantes linguísticas. Esse uso pode ser avaliado de três formas: a) inadequação às convenções da escrita; b) busca pela identidade do eu lírico; c) modo de alcançar efeitos sonoros significativos. A inadequação às convenções da escrita pode estar presente em qualquer produção de qualquer gênero. Decorre de uma concepção de escrita totalizante, que postula a elaboração do texto numa única vez, sem a necessidade de revisão. Na medida em que é significativa, na amostra, a inadequação mostra que a noção de revisão de texto ainda precisa ser trabalhada de forma mais efetiva. Como a adequação às convenções da escrita está prevista para todos os gêneros contemplados pela Olimpíada, refere-se a um trabalho transversal, e não a uma didática da escrita.

Já a busca pela identidade do eu lírico mostra que o aluno-poeta tenta uma adesão da linguagem ao lugar representado no poema. Muitas vezes a concordância, o uso de gírias, a assunção de uma fala (pelo uso do léxico) na variante coloquial ou regional apontava para a imagem que o eu lírico faz do lugar, buscando-se representar as vozes que seriam representativas desse espaço. Como a escola rejeita, na maioria das vezes, as variantes de menor prestígio, esses traços poderiam ser tomados como falta de elaboração. No entanto, a diferença entre este uso e o anterior, referente à inadequação, é a concorrência desses elementos, contribuindo para a construção do tema e a unidade do poema. 
Por fim, o modo de alcançar efeitos sonoros significativos traz a variante em seus traços mais perceptíveis - os que atingem o ouvido. Há supressão da marca de plural ou da desinência de infinitivo, ou ainda a supressão de uma sílaba como recurso para a manutenção do metro ou do ritmo. Esses casos são menos frequentes e apontam, assim como a busca da identidade, para o estabelecimento de um estilo que será comentado mais adiante.

As variantes linguísticas não são percebidas, na grande maioria das vezes, como recurso do poema, porém podem configurar o tema, ampliando os elementos à disposição do aluno-poeta, como se verificou na amostra.

\section{RIMA RICA, RIMA POBRE...}

As representações dos gêneros poéticos, na amostra, apontam para um recurso como o mais frequente: $98 \%$ dos poemas utilizam os mais variados tipos de rimas, sendo as mais comuns as consoantes em "ão”, “inha”, "dade" e "ar" (estes, em geral, verbos). Isso demonstra que os alunos-poetas atribuem ao elemento composicional figuras sonoras, o traço legitimador do poema. Essa concepção de poema não difere da representação mais usual, que circula socialmente. Muitas vezes ouvimos dizer: "É poema? Mas nem rima..." Dessa forma é possível destacar, dessas vozes que circulam na escola e seu entorno, que o tratamento dado aos outros elementos ficará em segundo plano. A tentativa de responder à representação mais frequente é um processo habitual dos usuários da língua, uma vez que, como afirma Bazerman (apud CARVALHO, 2005, p. 135), “uma forma textual que não é reconhecida como sendo de um tipo, tendo determinada força, não teria status nem valor social como gênero. Um gênero existe apenas à medida que seus usuários o reconhecem e o distinguem". A rima se torna, nesse contexto, recurso para angariar a aceitação do leitor, por ser elemento central para a representação do poema - nesse caso, texto em versos rimados.

O exame dessas ocorrências permitiu delinear a rima consoante como predominante e também observar outros usos que sugerem a existência produtiva de trabalho feito em sala de aula. 0 exemplo retirado da amostra se diferencia, nesse sentido, por trazer rimas variadas e um esquema de rimas mais sofisticado. Observem essa estrofe inicial: 
Fresca é a brlsa.

A flor e seu mais puro perfUME.

Na natureza tudo se ilumIna

Tudo é belo e causa ciÚMEs brlsa- rima toante com ilumina

perfume e ciúmes - rima consoante

C.S.B.S., aluna-poeta

A aluna-poeta constrói um esquema de rimas alternadas que se repetirá ao longo de todas as estrofes restantes do poema. A percepção desses esquemas nos poemas apresentados a ela pelo material da Olimpíada e/ou por outros, em sala, permitiu-lhe uma maior independência no momento de compor, que constrói nos recursos poéticos uma imagem mais consistente de ser poeta, pois se espera do poeta que domine os elementos composicionais. É o que a aluna-poeta fez, tangenciando a questão da representação ao colocála ao lado da imagem do eu lírico potente pelo domínio dos elementos de composição poética.

$\mathrm{Na}$ amostra, as rimas não se apresentam de forma constante nem variada. Esse decalque que os alunos fazem de alguns tipos de rima podem ser resultado da influência de outros gêneros, como a canção popular, que, em suas inúmeras manifestações, possui diferentes graus de sofisticação de rimas e recursos afins.

Além de ser um componente na construção da imagem do poeta, o uso consciente e regular das rimas põe em questão o tratamento do tema, uma vez que, nos poemas rimados, as palavras que rimam reforçam imagens e sentidos. É a percepção da estrutura em rede presente no texto poético, em que os elementos se hierarquizam e reforçam os sentidos, tal como Jolibert (1994, 1994a) o explicita, ao identificar os elementos constituintes do poema tanto para a proposta de leitura quanto para a de produção.

\section{NEM SÓ DE RIMA...}

Outro elemento que indica o comprometimento do aluno-poeta com o texto é o metro. Embora exista uma flutuação (de seis a oito sílabas poéticas podendo ser incluídos os metros de cinco e nove sílabas, embora menos 
frequentes), os versos tendem à redondilha maior, o verso de sete sílabas. Como afirma Mattoso, em Tratado de versificação,

sendo a redondilha maior o verso mais popular que existe, seu ritmo ecoa tão naturalmente nas glosas e trovas mais singelas quanto no romanceiro de cordel; seu metro funciona admiravelmente bem na música popular (ouçam-se canções como "Disparada” de Geraldo Vandré e Téo de Barros, "Travessia” de Fernando Brant e Milton Nascimento, “A estrada e o violeiro” de Sidney Miller e "Alegria, alegria" de Caetano Veloso) ou mesmo no sonetilho mais elaborado, como nestes exemplos (... $)^{1}$ (2010, p. 78).

Observem duas estrofes de um dos poemas da amostra:

\section{Metro}

$\mathrm{Mi} / \mathrm{nha} /$ ter/ra/ tem / RI /os

6

On/de/ na/da/ os /PEI/xes

6

Mi/nha/ter/ra/tem /a/mo/res

7

Por /on/de /can/tan/os/pas/as/RI/nhos

9

$\mathrm{Mi} / \mathrm{nha} / \mathrm{ter} / \mathrm{ra} / \mathrm{tem} / \mathrm{RU} / \mathrm{as}$

6

On/de an/do/ com /os / pés/des/CAL/ços

8

$\mathrm{Mi} / \mathrm{nha} / \mathrm{ter} / \mathrm{ra} /$ tem / CA/sas

6

On/de/ vi/vo/ com /li/ber/DA/de (...)

8

D.P.S., aluno-poeta

O metro, como se observa nas estrofes escolhidas do poema, oscila sempre em torno do metro popular, a redondilha maior. Algumas vezes, parece-nos que a hipótese do aluno é que a última sílaba tônica é contada e, em outros,

Mattoso se refere a "O violino" de Emílio Menezes e "A memória de uma ave” de Auta de Souza. 
que a disposição na página é o elemento definidor do metro, porque na grafia do aluno-poeta, versos longos podem ser mais curtos e vice-versa. No entanto, é inegável que, nos poemas da amostra, são estabelecidos limites para o metro e isso pode ser uma forma de aproximação dos poemas que circularam na sala de aula e que formaram uma imagem do que fosse poema.

A tentativa de estabelecer um metro de apelo popular pode significar decisões decorrentes de dois caminhos: 1) chamar o leitor para o poema (como vimos anteriormente em outros aspectos, como a rima); 2) compor dentro de modelos dados pelo encontro entre repertório e representação. Esse segundo caminho é significativo, porque o aluno-poeta já elaborou uma representação do que seja poema e essa representação se amplia com o trabalho em sala de aula. Pelas representações sociais, como afirma Moscovici,

\section{convencionalizamos objetos, pessoas ou acontecimentos que encontram. Elas lhe dão uma forma definitiva, as localizam em uma determinada categoria e gradualmente as colocam como um modelo de determinado tipo, distinto e partilhado por um grupo de pessoas. Todos os novos elementos se juntam a esse modelo e se sintetizam nele. (MOSCOVICI, 2007, p.34)}

O objeto a ser elaborado está envolto por essa convenção, que gramaticaliza outros elementos de aquisição posterior. A tendência, portanto, dos alunospoetas, é de trabalhar com as noções já instituídas, relendo os poemas apresentados pelo material da Olimpíada numa chave preexistente. Quebrar essa representação não é fácil, mas uma maneira de fazê-lo é pela justaposição a esse modelo de elementos que possam insinuar contradições capazes de levar as representações a mudanças. Nessa concepção, os poemas com os quais o aluno entra em contato e que respondem às suas expectativas são aqueles que ele utilizará como modelo, consciente ou não desse fato. Pelo poder de condensação e filtragem de experiência, as representações do que seja poema, tanto do professor como do aluno, merecem atenção e cuidado, por se tornarem, dentro desse quadro de coerções à escrita, instrumentos de manutenção ou de mudança.

\section{E O RITMO?}

Se o metro tende à regularidade, mesmo que de forma incipiente, tendo conquistado, como presença no poema, para boa parte dos alunos, o ritmo tem sido trabalhado superficialmente, carecendo de um olhar mais atento do professor nas oficinas.

O ritmo se espelha no corpo e pode garantir a corporificação de ritmos da 
cidade, de seus habitantes, de sua história. Se o trabalho rítmico não é feito pelos acentos secundários e as tônicas e átonas, o aluno-poeta, sentindo a necessidade de ritmo em seus versos, utiliza o paralelismo sintático para conduzir o poema.

Há vários exemplos que se destacam, na amostra. Apresentamos um deles, que retoma o paralelismo de uma outra obra, e que coaduna dois processos: intertextualidade e recurso sintático.

\section{MINHA TERRA TEM rios}

ONDE nada os peixes

MINHA TERRA TEM amores

Por onde cantan os passarinhos

\section{MINHA TERRA TEM ruas}

ONDE ando com os pés descalços

MINHA TERRA TEM casas

ONDE vivo com liberdade (...)

\section{D.P.S., aluno-autor}

O paralelismo sintático aparece nas duas estrofes (marcado em negrito e itálico) e faz ecoar a "Canção do Exílio", de Gonçalves Dias, que se transforma em modelo e homenagem em um processo que incorpora elementos parafrásticos e aponta para a estilização. ${ }^{6}$ Esse processo sintático comanda o processo de coesão do poema, garantindo um ritmo que é dado pela repetição das estruturas dos versos. 0 aluno-poeta convoca para o seu texto a autoridade do poeta romântico para tematizar a sua terra.

\section{QUARTETO OU QUADRA?}

Nos poemas da amostra, a configuração de estrofe predominante é o quarteto. Por vezes essa distribuição não isola subtemas ou aspectos nos limites 
dos quatro versos da estrofe, porém, em outros, lembrando a estrutura do parágrafo, cada um dos quartetos aborda um aspecto da cidade ou do lugar onde vive o aluno-poeta, transferindo para a organização do texto poético a estruturação dos textos da modalidade dissertativa. Essa transferência de estruturas dos gêneros prosaicos para o poema revela apropriação incipiente do aluno-poeta ou uma apropriação a cavalo: de um lado está a modalidade dissertativa e, de outro, a organização de gêneros poéticos populares como a quadra, cujas dimensões são os quatro versos apenas, e o cordel, que pode apresentar, a cada estrofe, um aspecto do tema.

É uma cidade agitada,

24 horas sem parar,

E tanta gente apressada

Que não dá pra contar!

[A cidade] é legal,

Os carros e ônibus a circular,

Ela é cidade industrial,

Com fábricas por todo o lugar. (...)

Gosto da cidade,

Tenho educação,

Não quero maldade,

Eu sou um cidadão!

ENCERRO, COM UMA DECLARAÇÃO,

Amo essa cidade,

O que tenho no coração,

É só felicidade! 
A estrofe final, além de indicar o encerramento (pela forma verbal "encerro"), remete, pelo uso do substantivo declaração, a um elemento que não seria característico dos gêneros poéticos. Essa indefinição entre prosa e poesia, muitas vezes, pode ser resultado da adoção de modelos de gêneros prosaicos como alimentação temática para a elaboração do poema, pois a intenção do texto é envolver o leitor na cadeia argumentativa que levará à adesão ao tema: a cidade.

Há vários gêneros prosaicos que se somam aos de modalidade dissertativa, conseguindo espaços no poema dos alunos. O de maior frequência é o da esfera publicitária, o slogan. A presença desse gênero desloca as condições de produção do texto poético. A gratuidade dos gêneros poéticos se esvai e o lugar onde vivo se torna uma mercadoria a ser vendida para o leitor - daí as várias formas para atraí-lo.

\section{ENTRE O TU CONTEMPORÂNEO E A PRINCESA}

A criação de uma imagem para a cidade não é tarefa fácil, se o aluno-poeta quer fugir dos clichês. Pelos anos que ostenta em sua história, a cidade pode ser reconstruída no poema de várias formas. A menos elaborada delas é o uso de adjetivos que a caracterizam de forma positiva. Esse caso, de grande frequência na amostra, sinaliza que o aluno-poeta tenta expor sua visão personalíssima, mas não consegue criar imagens que convençam o leitor, já que "cidade bela e formosa" é uma afirmação de caráter subjetivo que pode ser contestada a qualquer momento; mas o uso de uma figura de linguagem, uma metáfora ou uma metonímia, por exemplo, sustenta de forma mais clara processos de sedução do leitor para a ideia do poeta. 0 uso do diminutivo e das formas verbais no imperativo também são frequentes. Esses recursos estão ligados, respectivamente, à demonstração de uma afetividade quase infantil e aos gêneros publicitários.

Quanto à expressividade relacionada ao léxico, a personificação é a figura de linguagem mais usada, ainda que esses recursos sejam pouco frequentes. Em alguns casos, a cidade aparece como "princesa" ou como um interlocutor próximo, pelo uso do "tu". Com a cidade, os alunos-poetas conversam, louvam, agradecem, pedem. A cidade como princesa é perfeita e acolhedora. Entende a todos, em virtude de sua realeza. Em outros casos, os elementos associados à cidade são personificados e o aluno-poeta conversa com eles 
para entender e se aproximar do lugar onde vive. 0 exemplo a seguir ilustra esse segundo movimento nos poemas:

(...)

Venta, venta Ventania

Vim parar noutro lugar

$(\ldots)$

P.H.S.M., aluno-poeta

\section{SEMPRE EM FRENTE}

Um nível linguístico central nos gêneros poéticos é o sintático, que engloba desde o arranjo das palavras dentro dos sintagmas - passando pelo arranjo dos sintagmas nas orações e das orações num período -, até o nível de uma sintaxe textual: o arranjo entre as estrofes ou, ainda, a distribuição dos versos na página.

Na amostra, o predomínio é o da ordem direta. Não há, nesse nível, a elaboração que os poetas fazem, que é romper com a língua - representada, nesse momento, como social, convenção, regras. A ordem direta, pois, passa a facilitar sentidos que não precisam ser negociados. 0 estranhamento, a desautomatização da leitura, a proposta de outros caminhos para os olhos e para a compreensão não são adotados pelos alunos-poetas.

\section{A NEGOCIAÇÃO DAS VOZES E TEMAS}

A temática da Olimpíada traz à baila a negociação das vozes, como descrito por Fiad, como um dos aspectos da autoria: "duas atitudes de um autor seriam 'dar voz aos outros' e 'manter distância' em relação ao que dizem e em relação a seus interlocutores” (2008, p. 218). Como o trabalho em sala de aula prevê, no caderno Poetas da Escola, a conversa com os moradores e a investigação sobre a cidade, incluindo outras fontes de informação, além dos poemas de autores já consagrados, surgem outras vozes nos poemas; e isso se manifesta na superfície textual pela adoção da primeira pessoa do plural (nós, os cidadãos) e a terceira pessoa do singular (a cidade, o lugar).

Na maioria dos casos a voz do aluno-poeta foi silenciada nas formas verbais 
e nos pronomes pessoais. Quando aparece está marcada, de certa forma, por uma insuficiência que pode ser literal, na forma de um empobrecimento simples da posição autoral; ou figurada, em um artifício retórico que persiste desde a época de Aristóteles: declarar-se inadequado para a tarefa, afirmando suas características em outra área. É o que trata o exemplo a seguir:

\section{Poeta sei que não sou}

Sou mais um aventureiro

Da cidade ecológica

Que me encantou. (...)

L.G.J.V., aluno-poeta

As vozes também surgem no tratamento dado ao tema, como se outras vozes pudessem dizer a cidade, o lugar, com mais competência ou autoridade. Pela idade dos alunos-poetas, é possível compreender a força dos outros discursos, que podem levar a uma diluição da posição autoral no texto, como afirma Authier-Revuz:

Efetivamente, as formas não marcadas da heterogeneidade mostrada - discurso indireto livre, ironia... de um lado, metáforas, jogos de palavras ...de outro lado representam, pelo continuum, a incerteza que caracteriza a referência ao outro, uma outra forma de negociação com a heterogeneidade constitutiva; uma forma mais arriscada, porque joga com a diluição, com a dissolução do outro no um, onde este, precisamente aqui, pode ser enfaticamente confirmado mas também onde pode se perder. (1990, p.33)

A força desses discursos - alguns oriundos dos livros didáticos de História e Geografia; outros, oficiais, como os da prefeitura ou outro órgão assemelhado; outros, ainda, de poemas e poetas locais ou mesmo de canções populares sequestra a voz do aluno-poeta, que parafraseia o ouvido e o lido em arranjos que quebram a unidade de seu poema. Quando ele supera a paráfrase e entra em processo de paródia ou estilização, como se descobrisse os traços que constituem os poemas em que se inspira, tem-se um passo adiante no posicionamento autoral e no tratamento temático.

As vozes trazidas para o texto dos alunos-poetas constituem, na maioria dos casos, um coro de louvações. O lugar onde vive o aluno é cercado por uma aura de ufanismo, com raras exceções. Falar a terra em que se vive, para esses alunos, se concretiza na reiteração da cidade-utopia - um não-lugar, porque não corresponde à realidade da janela. A recriação ou a releitura da 
realidade pelos alunos é feita de forma a projetar desejos - paira, em chave saudosista e fundadora de discursos sobre a terra, o poema de Gonçalves Dias, “Canção do Exílio". Nos poemas da amostra, há dois caminhos para a louvação: o primeiro segue o tratamento dado à terra natal pelo poema gonçalviano, as belezas naturais são ressaltadas - não há outro lugar para se viver; o segundo, de caráter ufanista, projeta as excelências do lugar nas pessoas que o formam - o povo que construiu a cidade (passado de luta que resultou em vitória) e os trabalhadores que sustentam o lugar nos dias atuais (presente de luta que deverá resultar em vitória).

Quem seria o responsável poressas vozes institucionais ou institucionalizadas? A utilização desses discursos talvez decorra do fato de o aluno-poeta ter inscrito, no texto, um leitor adulto. 0 modelo pode ter sido o professor, pela oferta de textos que funcionam como alimentação temática. No entanto, nesse jogo de espelhamentos e projeções de imagens de leitor e de poema, o alunopoeta se apaga, pois sua vontade, seu olhar, são direcionados a elementos do lugar que supostamente agradam a esse leitor. Seria, esse leitor, a comissão que avalia esses alunos-poetas em primeira etapa e que mescla pessoas da comunidade e do espaço escolar? A resposta não está explícita nos textos; porém, o aluno não conversa com seus pares.

\section{O “COMO” DOS POEMAS}

Se retomarmos a ideia de que a autoria está no "como", podemos delinear alguns caminhos e propostas para o ensino dos gêneros poéticos a partir dessa experiência com a Olimpíada de 2010.

O movimento para o "como" poético já se iniciou nos textos da amostra, mas ainda está em seus primeiros esboços. As causas disso se encontram em várias projeções que os alunos-poetas fazem, chegando, na maioria dos casos, a uma pseudorregularidade. Muitos poderiam argumentar que o poema não necessita de estruturas regulares (rimas, ritmo, metro); o que corresponde à realidade da produção poética do século $X X$, em que regularidades e irregularidades coexistem nas obras dos poetas. Porém, a representação dos gêneros poéticos que os alunos projetaram em seus poemas, como texto em versos rimados, conduz a um processo de coerência pautado pela manutenção de certos elementos de composição estruturados na regularidade. A lógica criada no interior dos textos, no entanto, aponta para a pseudorregularidade, como uma promessa de algo que ainda não aconteceu. Vemos, nos versos, a semente que, supomos, já começou a brotar. 
Se basearmos a busca do "como" poético na expectativa de regularidade, podemos apontar para os recursos de estilo sonoros, bem como o paralelismo sintático, como traços já em fase de desenvolvimento nos poemas. Parecenos que os elementos expressivos relacionados a essas figuras de linguagem (aliteração, assonância e rimas) e paralelismo - todas baseadas na repetição - permitem que a atenção dos alunos se amplie para vários planos (ou níveis linguísticos) presentes nos poemas. A atenção se volta para a forma de escrever o lugar e não somente no que se diz sobre o lugar, uma vez que as palavras que rimam e as estruturas que se repetem nos versos instituem-se como portadoras de sentido, soando ou imprimindo sua presença aos olhos e ouvidos do leitor.

\section{LUGARES A QUE ELES CHEGARAM}

Os processos desenvolvidos no âmbito da Olimpíada parecem, portanto, ter conduzido a um subgênero de tom laudatório, com traços do cordel e da quadra. Nessas formas poéticas regulares, os traços mais evidentes e legitimados são a rima, que se apresenta como uma das maneiras de garantir a vinculação com esses gêneros, e a variante linguística coloquial e/ou regional, típica também desses gêneros poéticos de caráter popular.

A presença desses gêneros poéticos estaria fundada em uma suposta facilidade atribuída a esses gêneros? Estariam mais próximos do repertório dos alunos? Seria a passagem dos gêneros primários para os secundários, 0 traço facilitador? A vinculação com a memória dos gêneros poéticos primários, como o repente, em que prevalece o improviso e cujos desdobramentos estão aparentados ao cordel, pode ser uma resposta afirmativa a essa questão. 0 outro gênero que está presente, a quadra, pela sua extensão, promove a memorização, que parece reforçar os traços eleitos como legitimadores do poema para os alunos - a percepção do jogo sonoro das rimas e das estruturas paralelísticas. Confere, também, coesão a seus versos, o que parece traduzirse em suficiência para os poetas mirins.

Nesses poemas, o tema - o lugar onde vivo - foi traduzido nos versos como a cidade, o bairro, a rua, um local pitoresco e até um evento (jantar de gerações). Nesses espaços tudo se apresenta como louvável (habitantes, animais, a natureza). Há, em vários níveis linguísticos, um trabalho sem complexidade: os adjetivos são os mais comuns; a ordem das orações, como já apontado, é direta. Esse tratamento linguístico revela a interferência de tratamentos temáticos de gêneros de duas esferas: a publicitária (que, como 
indicado, torna a cidade um produto) e a jornalística (das colunas sociais). Os poemas que se sobressaem propõem a releitura desses gêneros pelos gêneros poéticos. A cidade é um produto, mas de seu povo; e não se vende, admira-se. E, junto com outros, constrói-se. Os habitantes da cidade são dignos de homenagens, não por algum traço de nascimento ou riqueza, mas por sua presença na vida cotidiana. Esses deslocamentos proporcionam outros pontos de vista, que desconstroem as certezas de discursos oficiais e oferecem ao leitor um espelho, e não mais um modelo.

As irrupções dos elementos da estrutura composicional dos gêneros poéticos se apresentam como uma das evidências que o trabalho já começou a ser feito. Os alunos-poetas foram sensibilizados para a elaboração do poema e, como poetas, querem agir sobre os leitores, fazer com que haja adesão aos seus temas e versos. Essas irrupções ficam claras na gravação dos poemas pelos semifinalistas. ${ }^{7}$ Cada um dos alunos corporificou seu poema com o ritmo e a força idealizados, embora nem sempre efetivados no papel.

\section{QUEM FICOU DE FORA?}

\section{O LÚDICO}

José Paulo Paes, poeta paulista, que escreveu para crianças e adultos, acreditava no lúdico associado ao humor como resposta para a poesia dedicada a crianças (e também aos adultos). Ele afirma: “Coube a Monteiro Lobato, senão o fundador, certamente o mestre até hoje da literatura brasileira para crianças, mostrar que o humor é o principal ingrediente dessa literatura, que antes dele vivia encalhada na sentimentalidade e no moralismo dos piores lugares-comuns" (PAES, 1996, p. 20). E sentimos em sua fala os problemas temáticos dos poemas dos alunos. Qual a solução? Segundo Paes, são as brincadeiras verbais que trazem "os efeitos de surpresa e de extravagância" que ele acredita “divertir a imaginação infantil” (PAES, 1996, p. 21).

Para alunos de quinto e sexto anos, poder brincar com o nonsense, com os jogos de palavras que redescobrem o real, com o poder de trocar o mundo de lugar traz potência, um caminho para se apropriar do mundo e descobrir sua própria voz.

Cf. no site da Comunidade Escrevendo o futuro, junto aos Cadernos de Orientação da Olimpíada 2012. Disponível em: http://escrevendo.cenpec.org.br/index. php?option=com_content\&view=article $\& i d=283$ :versos-de-diversos-lugares $\&$ catid $=12$ : olimpiada\&ltemid=14 Acesso em fevereiro de 2012. 


\section{A ESCOLHA DE UM GÊNERO POÉTICO}

Trabalhar com um único e mesmo gênero poético poderia privá-los de experiências diversificadas; mas lhes daria uma direção mais segura, assim como a oportunidade de desenvolver certos aspectos mais profundamente. Como equilibrar essas duas situações? Os alunos-poetas têm predileções, poetas ou gêneros, que devem ser incorporadas no trabalho pedagógico com seus próprios textos, pois, na tradição da lírica no Ocidente, os poetas conversaram com seus modelos em homenagens e rebeldias que foram muito produtivas para a tradição e inovação da poesia. O professor, verificando essas propensões, pode estimular o poeta para esses diálogos.

\section{QUE LUGARES SURGIRÃO NOS POEMAS, AGORA?}

Como os gêneros da esfera literária demandam do leitor uma atitude responsiva retardada (BAKHTIN, 2003), estimular os alunos e os professores a participarem mais de uma vez da Olimpíada poderia ser uma resposta a essas questões. Voltar ao poema em sala de aula, nessas duas situações, e sem o estímulo da competição, garantiria a percepção mais completa do gênero, pois, como afirmam Schneuwly \& Dolz (2004), o ensino em espiral permite que, nas atividades de sala de aula, possamos descobrir novos aspectos em relação a um gênero, já que, ao voltarmos para ele, avançamos em elementos não experimentados antes. No caso dos poéticos, a abordagem lúdica de cada um dos elementos composicionais poderia envolver brincadeiras para descobrir palavras novas, palavras que rimam, estruturas que podem ser preenchidas de forma inusitada (como "amo a minha cidade como se ama um cachorro de rua"), jogos de associação de imagens, jogos que permitam a sensibilização para lembranças e sensações, ${ }^{8}$ desconstrução de poemas, uso da palavra alheia transformada, jogos de associação sonora e semântica, entre outros, que o professor mobilizaria com base no desempenho e interesse de cada turma.

A leitura do poema em voz alta é um procedimento que precisa ganhar espaço na sala de aula. Além da corporificação do poema pelo próprio aluno-poeta, é preciso ouvir as várias vozes, a do professor, a dos colegas. É preciso ouvir o mesmo poema em muitas vozes e interpretações, para entender a singularidade apontada nos critérios propostos para a avaliação. Dar corpo é importante e tem como efeito colateral, a responsabilização do aluno-poeta por aquele texto seu ou alheio que ele passará a abrigar em seu corpo. A

Cf. JOLIBERT, 1994 e $1994 a$. 
leitura, a partir daí, pode ser um procedimento de revisão e de autoavaliação do texto poético e resultará da percepção do aluno antes de outras de caráter avaliativo formal (como a do professor). Recuperar espaços para os poemas como os saraus e os concursos de declamação pode ampliar a visão que os alunos, os pais e a comunidade têm desses gêneros tão singulares.

Quando começamos a ler os poemas da amostra, buscávamos a voz dos alunos-poetas nos coros que encontrávamos. No trajeto, descobrimos que as vozes estão lá e que escrever poema é lutar com as palavras, é encontrar modelos, é superá-los na exata medida do verso, da rima, do metro e do ritmo, num inesgotável diálogo entre lugares a que já fomos e outros, pasargadianos, a que iremos para sermos amigos do rei. 


\section{Writing poems: voices in search of an author}

\section{ABSTRACT}

The decision to use genre as a basis for developing writing skills entails methodological choices which will, in turn, impact the work by the studentpoets. An analysis of the poems presented at the Olimpiada de Lingua Portuguesa (2010) allowed for the creation of a list of choices made within the poem-writing process - both by teachers and by students - which point to authorship as the central feature for this genre. In order to identify the authorwho sustains the poem, as Faraco (2005, p. 45) argues based on the bakhtinian concept of authorship, and as Fiad (2008, p.218) also sustains - these features would be on the "how", on the "process of refracted transpositions", on "the uniqueness of style" and also on the "value-assessment bent". In each of the poems selected, these elements were examined as they emerge from different voices which intertwine in the poems and point to the subjection or the solution to the voice of the student-poet.

\section{KEYWORDS:}

Authorship. Poetic genres. Poem-writing process. 
AUTHIER-REVUZ, Jaqueline. "Heterogeneidade(s) enunciativa(s)". Trad. de Celene M. Cruz e João Wanderley Geraldi. Cadernos de Estudos Linguísticos, Campinas, v. 19, p. 25-42, jul./dez. 1990.

BAKHTIN, Mikhail. Estética da criação verbal. Introd. e trad. do russo: Paulo Bezerra; prefácio à ed. francesa: Tzvetan Todorov. 4a ed. São Paulo: Martins Fontes, 2003.

CARVALHO, Gisele de. Gênero como ação social em Miller e Bazerman: o conceito, uma sugestão metodológica e um exemplo de aplicação. In: MEURER, J.L.; BONINI, A.; MOTTA-ROTH, D. (Org.). Gêneros: teorias, métodos e debates. São Paulo: Parábola, 2005. p. 130-149. (Lingua[gem], 14).

CENPEC. Poetas da escola. Caderno do professor: orientações para produção de textos. Equipe de produção: Anna Helena Altenfelder e Maria Alice Armelin. São Paulo: Cenpec, 2010. Coleção da Olimpíada.

COHEN, Jean. Estrutura da linguagem poética. São Paulo: Cultrix, 1978.

FARACO, Carlos Alberto. Autor e Autoria. In: BRAIT, Beth (Org.). Bakhtin: conceitos -chave. São Paulo: Contexto, 2005.

FIAD, Raquel Salek. Ensino e autoria. In: TFOUNI, Leda Verdiani (Org.). Múltiplas faces da autoria. ljuí: Ed. Inijuí, 2008. (Linguagens).

GOldSTEIN, N. Poema. In: LAgINESTRA, M. A. et al. Avaliação de textos: Orientações para selação de textos nos gêneros : Poema, Memórias literárias, Crônicas e Artigo de opinião. São Paulo: Cenpec, 2010. 1 CD-ROM (Desenvolvimento de material didático ou instrucional para orientação para professores).

JOLIBERT, Josette (coord.). Formando crianças leitoras. Trad. Bruno C. Magne. Porto Alegre: Artes Médicas, 1994. v. 1.

JOLIBERT, Josette. Formando crianças produtoras de texto. Trad. Walkiria M.F. Settineri e Bruno C. Magne. Porto Alegre: Artes Médicas, 1994a. v. 2.

MATTOSO, Glauco. Tratado de versificação. Prefácio e Introdução de Manuel Cavalcanti Proença. São Paulo: Annablume, 2010. (Coleção [e] Editorial). MOSCOVICI, Serge. Representações sociais: investigações em psicologia 
social. 5a ed. Ed. em ingl. por Gerard Duveen; Trad. De Pedrinho Guareschi. Petrópolis: Vozes, 2007.

PAES, José Paulo. Quem, eu? Um poeta como outro qualquer. São Paulo: Atual Editora, 1995. (Passando a Limpo).

SANT'ANNA, Affonso Romano de. Paródia, paráfrase \& cia. 8 ed. São Paulo: Ática, 2007.

SCHNEUWLY, Bernard; DOLZ, Joaquim. et al. Gêneros orais e escritos na escola. Trad. e org. Roxane Rojo e Glaís Sales Cordeiro. Campinas: Mercado de Letras, 2004. (As Faces da Linguística Aplicada).

Recebido em: FEVEREIRO de 2012.

Aprovado em: MAIO de 2012. 